\title{
Improvement of Color Fastness for Deep Black Shade of Cotton Fabric
}

\author{
Lina Lin ${ }^{1, a}$, Md. Ziaur Rahman ${ }^{1, b}$, Shu Wen ${ }^{1, c}$, Md. Nahid Pervez ${ }^{1, d}$, Jin Li $^{2, e_{*}}$, \\ Yingjie Cai ${ }^{1,2, f}$ \\ ${ }^{1}$ Hubei Key Laboratory of Biomass Fibers and Eco-dyeing \& Finishing, Wuhan Textile University, \\ Wuhan, 430073, China \\ ${ }^{2}$ Engineering Research Centre for Clean Production of Textile Dyeing \&Printing, Ministry of \\ Education, Wuhan Textile University, Wuhan, 430073, China \\ aemail: linalin@wtu.edu.cn, bemail: Ziaurmmm@yahoo.com, 'email: 869882975@qq.com, \\ demail: nahid.tex92@gmail.com, ${ }^{\dagger}$ email: yingjiecai@wtu.edu.cn \\ *Corresponding author, ${ }^{e}$ E-mail: lijin@wtu.edu.cn
}

Keywords: Cotton; Deep Shade; Reactive Dye; Wash Fastness; Rubbing Fastness

\begin{abstract}
Cotton fabric was dyed with C.I. Reactive Black 5 with different dye mass, followed the treatments of soaping, dye fixing, and wet rubbing improving. The wash fastness, rubbing fastness, and colour uniformity of dyed cotton were inspected. The results show that the entire utilized textile auxiliaries did not cause a yellowness problem. After application of the dye fixative and wet rubbing improver, to the deep black shade cotton (15\% o.m.f), the wash fastnesses were all at grade 5 , and reached at grade 5 and 3-4 of dry and wet of rubbing fastness respectively. The wet rubbing improver improved half grade of wet rubbing for dye o.m.f less than $8 \%$, but did not have any contribution for deep shade.
\end{abstract}

\section{Introduction}

Reactive dyes are most commonly applied because of their low cost, easy to apply, excellent wet colour fastness, and bright color [1-5]. In the process of reactive dyeing, the reactive dye always tends to be hydrolyzed [6,7]. After dyeing, the unfixed reactive dye (hydrolyzed and unreacted reactive dye) exists in the interior and surface of fibre, especially in deep shade dyeing, which has to be removed. Without effective dye removal, it results in a poor colour fastness; thus an effective washing, such as soaping treatment, is applied to assistance of washing off unfixed dye [8,9]. However, it is hard to achieve the excellent colour fastness since if the fabric holds $0.003 \%$ dye on the mass of fabric (o.m.f) will produce a stain same as to a grey scale rating of 4 . In the traditional method of acquiring high colour fastness, after reactive dyeing the dyed substance is neutralization washed and soaped to remove the unfixed dyes as much as possible, subsequently dye fixing treatment is conducted to prevent the unfixed dyes [10-12].

This research aims to prepare a deep black shade cotton fabric with high colour fastness, therefore the textile auxiliaries from two famous companies (Dymatic and Transfar) in China are selected, and their performances in soaping, fixing and wet rubbing improving on deep black shade cotton fabric are investigated in the promotion of the wash fastness and rubbing fastness.

\section{Experimental}

\section{Materials.}

A desized, scoured, bleached and unmercerized woven cotton fabric (100\%) was dyed with C. I. Reactive Black 5 (Shanghai Jiaying Chemical Company) without purification. The textile auxiliaries of DM1578 (soaping agent), DM1518 (dye fixative), and DM2588X (wet rubbing fastness improver) are from Dymatic Chemical Company; TF231A (soaping agent) and TF234FK (dye fixative) are from Zhejiang Transfar Company. Dimethylformamide (DMF, Sinopharm Chemical Reagent Company, 99.5\%) was used in reflux. Other chemicals were general laboratory grade. 


\section{Dyeing.}

Cotton fabric was dyed in a rotary infrared laboratory dyeing machine with C.I. Reactive Black 5 in different dye amount on the mass of fabric (o.m.f) in 3\%, 5\%, 8\%, 10\%, 12\%, and 15\% at a liquor ratio of $1: 20$ with $80 \mathrm{~g} \mathrm{~L}^{-1}$ of $\mathrm{NaCl}, 20 \mathrm{~g} \mathrm{~L}^{-1}$ of $\mathrm{Na}_{2} \mathrm{CO}_{3}$ for $60 \mathrm{~min}$ at $60^{\circ} \mathrm{C}$. After dyeing, the dyed fabric was neutralization washed at room temperature, and then rinsed thoroughly in tap water. The dyeing process is described in Fig. 1.

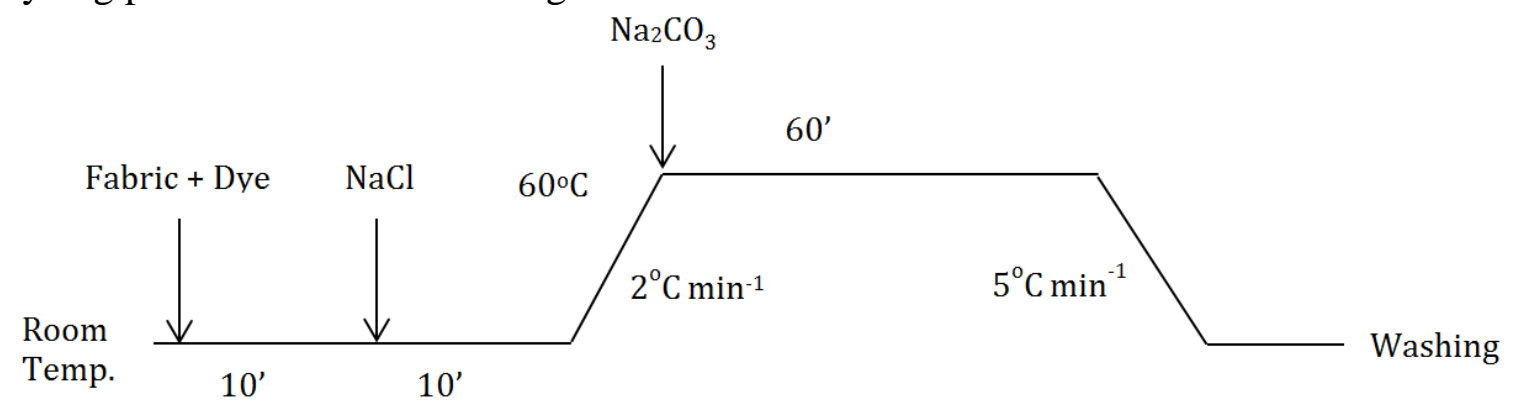

Fig. 1. Dyeing process

\section{Soaping.}

The dyed cotton was soaped at a liquor ratio of $1: 30$ and $2 \mathrm{~g} \mathrm{~L}^{-1}$ of soaping agent at $100^{\circ} \mathrm{C}$ for 30 min, and then rinsed in tap water, and air dried.

\section{Reflux.}

The dyed cotton was refluxed with 50\% aqueous DMF solution at a liquor ratio of 1:40 for 20 min, and repeated it until all the unfixed dye was completely removed [8].

\section{Dye Fixing Treatment.}

After soaping, the dyed cotton was treated using $2 \%$ o.m.f of the dye fixative at a liquor ratio of 1:30 at $55^{\circ} \mathrm{C}$ for $15 \mathrm{~min}$, and then rinsed in tap water, and air dried.

\section{Wet Rubbing Improvement.}

After dye fixing treatment, the dyed cotton was immersed in the wet rubbing improver solution $\left(40 \mathrm{~g} \mathrm{~L}^{-1}\right.$ ), padded with $80 \%$ wet pick-up, dried at $100^{\circ} \mathrm{C}$ for $5 \mathrm{~min}$ and cured at $150^{\circ} \mathrm{C}$ for $2 \mathrm{~min}$, rinsed in tap water, and air dried.

\section{Color Uniformity.}

The standard deviation was used to calculate the color uniformity of the dyed cotton by K/S values (datacolor, USA) measuring on 20 random positions at maximum absorption values using Eq. 1 and Eq. 2 [9].

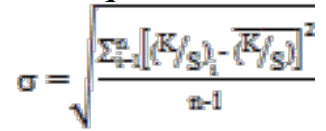

$$
\begin{aligned}
& \overline{(\mathrm{K} / \mathrm{S}})=-\frac{1}{\mathrm{n}} \sum_{\mathrm{i}-1}^{\mathrm{n}}(\mathrm{K} / \mathrm{S})_{\mathrm{i}}
\end{aligned}
$$

Where $\sigma$ is the standard deviation, $n$ is the number of measured spots, and $(K / S)_{i}$ is the K/S value of each random spot.

\section{Colour Fastness.}

Wash fastness and rubbing fastness (dry and wet) of dye cotton were measured as per the ISO 105-C06 and ISO 105-X12 respectively.

\section{Results and Discussion}

\section{Soaping.}

After soaping treatment, the K/S values of dyed samples in varied dye o.m.f are displayed in Fig. 2. Fabric $_{1}$, Fabric $_{2}$ and Fabric 3 refers to the dyed cotton which were refluxed, soaped with DM1578 and TF231A respectively; Fabric 4 is the fabric of dye fixing treated with DM2518 on Fabric 2 ; Fabric $_{5}$ is the fabric of dye fixing treated with TF234FK on Fabric 3 ; Fabric 6 and Fabric ${ }_{7}$ are the fabrics of Fabric $_{4}$ and Fabric 5 treated with DM2588X respectively. After reflux, the K/S values of dyed cotton (Fabric 1 ) indicate that the dye fixed on cotton increases with dye o.m.f increasing but reach a level after dye o.m.f $8 \%$ possibly due to the saturated fixation of reactive dye. The soaping 
agents of DM1578 ( Fabric $_{2}$ ) and TF231A (Fabric 3 ) express a good and similar performance on washing off unfixed dye, but it is worse in contrast with reflux especially at higher dye o.m.f.

In the end of dyeing, the unfixed dyes mainly existed in the interior and surface of cotton fibre via Van Der Waals force between dye and fibre, and/or between dye and dye. Under the reflux, the unfixed dye in the interior can be removed to the reflux mix solution, which shows its excellent dye removal efficiency. Soaping agent with major surfactant content has a good property in removing dust, but has not ability to completely remove the unfixed dye. It notes that the performance of both soaping agents was excellent at 3\% dye o.m.f since their K/S values are similar with that in reflux, which is the dye quality normally applied in the traditional dyeing process.

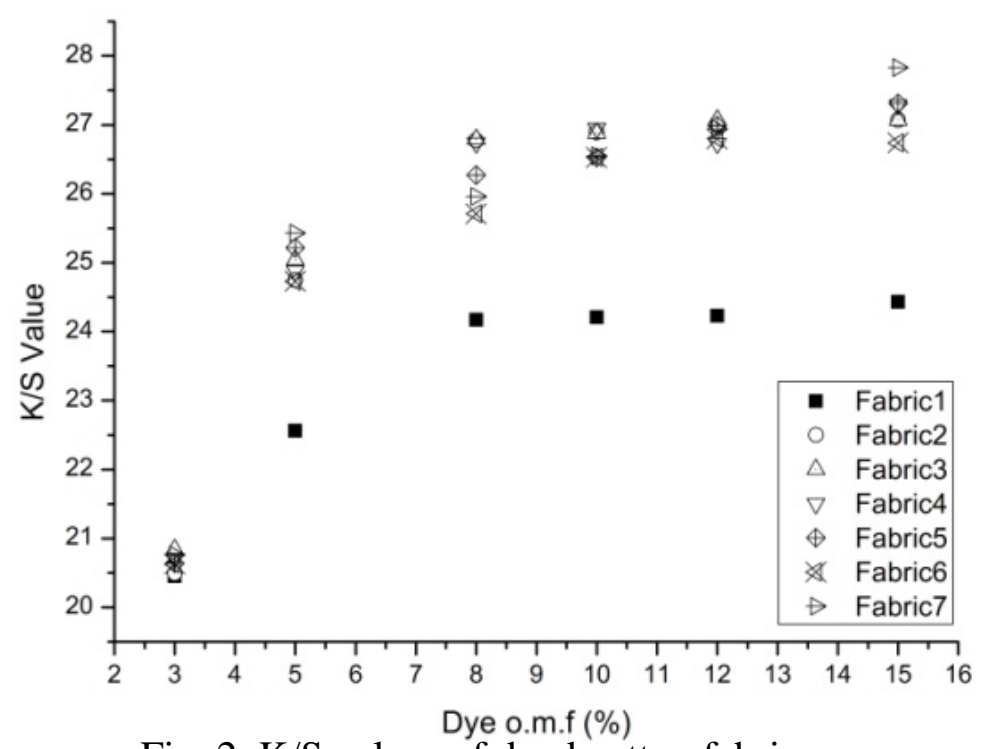

Fig. 2. K/S values of dyed cotton fabric

The unfixed dyes without effective remove will reduce the colour fastness of dyed substance, such as wash fastness and rubbing fastness. Table 1 lists the wash fastness (staining on bleached cotton fibre of multi fabric), rubbing fastness (dry and wet) and colour uniformity of dyed fabrics with different colour shade. The wash fastnesses of dyed cotton treated by soaping with detergents are similar and gradually decrease from grade 5 to grade 4 with an increase of color shade. In contrast with reflux, the wash fastness is slightly worse, which are all at grade 5 due to its excellent dye removal property.

After soaping with DM1578 (Fabric 2 ) and TF231A (Fabric 3 ), the rubbing fastness of corresponding dyed samples are at grade 5 and 4-5 in dry, and grade 3-4 and 3 in wet. The dyed sample treated with reflux always shows its transcendent performance in rubbing fastness, which are all at grade 5 in dry and grade 4-5 in wet. It is difficult to obtain grade 5 of wet rubbing fastness because during rubbing, little dyed fibre was rubbed out the dyed fabric and stained on the wet white test cotton fabric. Furthermore, exception of reflux, the rubbing fastness decreased about half grade with increase of dye shade, which similarly occurred in the wash fastness. All in all, an effective dye removal treatment is conducive to heighten the wash fastness and rubbing fastness.

Another necessarily considered index of dyeing is colour uniformity, especially in deep shade dyeing. The standard deviation values of dyed samples are less than 0.6 , which indicates that all samples were levelly dyeing. The best colour uniformity of dyed samples was present in the reflux treatment since the average standard deviation value (0.37) of differed dye o.m.f is the lowest among the treatments.

\section{Dye Fixing Treatment.}

Comparison between the soaped samples before (Fabric 2 and Fabric $_{3}$ ) and after (Fabric 4 and Fabric $_{5}$ ) dye fixing treatment, the corresponding K/S values in Fig. 2 are similar, which means the colour of dyed samples was not changed by the dye fixing application despite of yellowness appearance occurs in some cases with other dye fixative. The primary function of the dye fixative is to fix the unfixed dyes, which performance is characterized in the rate of wash fastness and rubbing fastness. After dye fixing treatment, the wash fastnesses were improved, which all were at grade 5 
(the wash fastness of Fabric $_{4}$ and Fabric $_{5}$ ). It hints that both dye fixatives can promote wash fastness of dyed sample at least 1 grade.

Rubbing fastness is another important index to inspect the performance of dye fixing treatment. After treatment, both dye fixatives exhibit an enhancement of dry and wet rubbing fastness, which were raised to grade 5 from grade $4-5$ at dye o.m.f $12 \%$ and $15 \%$ in dry; meanwhile the grade was up to 3-4 for all dye shades in wet. This result demonstrates that both dye fixatives can advance half grade of dry and wet rubbing fastness of dyed sample in deep shade.

Table 1 Wash fastness, rubbing fastness and colour uniformity of dyed cotton fabrics

\begin{tabular}{|c|c|c|c|c|c|c|c|c|c|c|c|}
\hline \multirow[t]{2}{*}{ Fabric } & \multirow{2}{*}{$\begin{array}{l}\text { Dye } \\
\text { o.m.f } \\
(\%)\end{array}$} & \multirow[t]{2}{*}{$\begin{array}{l}\text { Wash } \\
\text { Fastness }\end{array}$} & \multicolumn{2}{|c|}{$\begin{array}{l}\text { Rubbing } \\
\text { Fastness }\end{array}$} & \multirow[t]{2}{*}{$\begin{array}{l}\text { Colour } \\
\text { Uniformity }\end{array}$} & \multirow[t]{2}{*}{ Fabric } & \multirow{2}{*}{$\begin{array}{l}\text { Dye } \\
\text { o.m.f } \\
(\%)\end{array}$} & \multirow[t]{2}{*}{$\begin{array}{l}\text { Wash } \\
\text { Fastness }\end{array}$} & \multicolumn{2}{|c|}{$\begin{array}{l}\text { Rubbing } \\
\text { Fastness }\end{array}$} & \multirow[t]{2}{*}{$\begin{array}{l}\text { Colour } \\
\text { Uniformity }\end{array}$} \\
\hline & & & $\overline{\text { Dry }}$ & Wet & & & & & $\overline{\text { Dry }}$ & Wet & \\
\hline \multirow[t]{6}{*}{ Fabric $_{1}$} & 3 & 5 & 5 & $4-5$ & 0.42 & Fabric $_{5}$ & 3 & 5 & 5 & $3-4$ & 0.49 \\
\hline & 5 & 5 & 5 & $4-5$ & 0.26 & & 5 & 5 & 5 & $3-4$ & 0.49 \\
\hline & 8 & 5 & 5 & $4-5$ & 0.37 & & 8 & 5 & 5 & $3-4$ & 0.46 \\
\hline & 10 & 5 & 5 & $4-5$ & 0.37 & & 10 & 5 & 5 & $3-4$ & 0.54 \\
\hline & 12 & 5 & 5 & $4-5$ & 0.38 & & 12 & 5 & 5 & $3-4$ & 0.56 \\
\hline & 15 & 5 & 5 & $4-5$ & 0.42 & & 15 & 5 & 5 & $3-4$ & 0.50 \\
\hline \multirow[t]{6}{*}{ Fabric $_{2}$} & 3 & 5 & 5 & $3-4$ & 0.56 & Fabric $_{6}$ & 3 & 5 & 5 & 4 & 0.49 \\
\hline & 5 & $4-5$ & 5 & $3-4$ & 0.44 & & 5 & 5 & 5 & 4 & 0.37 \\
\hline & 8 & $4-5$ & 5 & 3 & 0.39 & & 8 & 5 & 5 & 4 & 0.37 \\
\hline & 10 & 4 & 5 & 3 & 0.36 & & 10 & 5 & 5 & $3-4$ & 0.38 \\
\hline & 12 & 4 & $4-5$ & 3 & 0.31 & & 12 & 5 & 5 & $3-4$ & 0.40 \\
\hline & 15 & 4 & $4-5$ & 3 & 0.45 & & 15 & 5 & 5 & $3-4$ & 0.44 \\
\hline \multirow[t]{6}{*}{ Fabric $_{3}$} & 3 & 5 & 5 & $3-4$ & 0.54 & Fabric $_{7}$ & 3 & 5 & 5 & 4 & 0.46 \\
\hline & 5 & $4-5$ & 5 & $3-4$ & 0.47 & & 5 & 5 & 5 & 4 & 0.27 \\
\hline & 8 & $4-5$ & 5 & 3 & 0.34 & & 8 & 5 & 5 & 4 & 0.27 \\
\hline & 10 & 4 & 5 & 3 & 0.33 & & 10 & 5 & 5 & $3-4$ & 0.30 \\
\hline & 12 & 4 & $4-5$ & 3 & 0.31 & & 12 & 5 & 5 & $3-4$ & 0.38 \\
\hline & 15 & 4 & $4-5$ & 3 & 0.54 & & 15 & 5 & 5 & $3-4$ & 0.43 \\
\hline \multirow[t]{6}{*}{ Fabric $_{4}$} & 3 & 5 & 5 & $3-4$ & 0.51 & & & & & & \\
\hline & 5 & 5 & 5 & $3-4$ & 0.45 & & & & & & \\
\hline & 8 & 5 & 5 & $3-4$ & 0.45 & & & & & & \\
\hline & 10 & 5 & 5 & $3-4$ & 0.45 & & & & & & \\
\hline & 12 & 5 & 5 & $3-4$ & 0.36 & & & & & & \\
\hline & 15 & 5 & 5 & $3-4$ & 0.51 & & & & & & \\
\hline
\end{tabular}

\section{Wet Rubbing Improving Treatment.}

The K/S values of dyed samples treated with DM2588X demonstrate that the colour strengths did not change, i.e. no yellowness appearance. Addition, it represents excellent wash fastness, all are at grade 5 in Fabric $_{6}$ and Fabric 7 . Attention on the wet rubbing fastness (Fabric 6 and Fabric $_{7}$ ), the grade ascends to grade 4 in the dye o.m.f $3 \%, 5 \%$ and $8 \%$, but stays at grade $3-4$ in the rest dye o.m.f conditions. It means that under the application conditions, both wet rubbing improver cannot contribute the enhancement of wet rubbing fastness when the dye shade is more than $8 \%$ dye o.m.f. During wet rubbing process, the unfixed dye tends to leave from the dry dyed sample and stays on the wet white test fabric, resulting in staining problem. The wet rubbing improver is to seal off the anionic groups of the unfixed dye, such as sulfo groups, to impede the unfixed dye transferring on the wet rubbing test fabric. As mentions previously, partial unfixed dyes existed in the interior of 
fibre, which anionic groups were possibly not blocked out by the wet rubbing improver in deep shade, causing no contribution on wet rubbing fastness in high dye o.m.f.

\section{Conclusion}

After treatments of soaping, dye fixing, and wet rubbing improving, the colour fastnesses of dyed cotton fabric with different dye o.m.f were improved without doubt. The optimum colour fastnesses of the dyed cotton fabrics with these treatments were all at grade 5 in wash fastness, all at grade 5 in dry rubbing fastness, and at grade 4 in wet rubbing fastness in the dye o.m.f range of $3 \%$ to $8 \%$. The soaping agents and dye fixatives showed the similar performances, and the dye fixatives promoted half to one grade of wash fastness and wet rubbing fastness. The wet rubbing improver enhanced half grade of wet rubbing fastness in the dye mass used lower than dye o.m.f 8\%.

\section{Acknowledgments}

This work was sponsored by the Hubei Key Laboratory of Biomass Fibers and Eco-dyeing \& Finishing, Wuhan Textile University (Project No. 2014STRZ003), China National Textile \& Apparel Council (Project No. 2015061), and Collaborative Innovation Plan of Hubei Province for Key Technology of Eco-Ramie Industry (E JIAO KE HAN 2014 No.8)

\section{References}

[1] Longyun Hao, Rui Wang, Kuanjun Fang, Jingquan Liu, Yong Sun, Yajing Men. The synchronized wash-off of reactive-dyed cotton fabrics and decolorization of resultant wastewater using titanium dioxide nano-fibers [J]. Carbohydrate polymers, 2015, 125: 367-375.

[2] Long Fang, Xiaodong Zhang, Deshuai Sun. Chemical modification of cotton fabrics for improving utilization of reactive dyes [J]. Carbohydrate polymers, 2013, 91 (1): 363-369.

[3] Huitu Wang, DM Lewis. Chemical modification of cotton to improve fibre dyeability [J]. Coloration Technology, 2002, 118 (4): 159-168.

[4] SM Burkinshaw, J Howroyd, N Kumar, O Kabambe. The wash-off of dyeings using interstitial water part 2: Bis (aminochlorotriazine) reactive dyes on cotton [J]. Dyes and Pigments, 2011, 91 (2): 134-144.

[5] Md Shahidullah, Rabiul Islam, MM Alamgir Sayeed, Kamal Uddin, ABM Abdullah. Improvement of light fastness properties of dyed jute fabrics through pretreatment [J]. Journal of Applied Sciences, 2007, 7: 3791-3795.

[6] John Shore. Cellulosics dyeing, Bradford: Society of Dyers and Colourists, 1995.

[7] Marija Gorenšek. Dye-fibre bond stabilities of some reactive dyes on cotton [J]. Dyes and pigments, 1999, 40 (2): 225-233.

[8] VA Shenai. Technology of textile processing, Bombay: Sevak Publications, 1993.

[9] K Venkataraman. The chemistry of synthetic dyes, Elsevier, 2012.

[10]E R Trotman. Dyeing and chemical technology of textile fibres, London: Charles Griffin \& Company Limited, 1975.

[11]WD Schindler, PJ Hauser. Chemical finishing of textiles, Elsevier, 2004.

[12] Mehmet Akalin, Nigar Merdan, Dilara Kocak, Ismail Usta. Effects of ultrasonic energy on the wash fastness of reactive dyes [J]. Ultrasonics, 2004, 42 (1): 161-164.

[13]Reda M El-Shishtawy, YA Youssef, Nahed SE Ahmed, AA Mousa. The use of sodium edate in dyeing: II. Union dyeing of cotton/wool blend with hetero bi-functional reactive dyes [J]. Dyes and Pigments, 2007, 72 (1): 57-65.

[14]Nebojša Ristić, Ivanka Ristić. Cationic Modification of cotton fabrics and reactive dyeing characteristics [J]. Journal of Engineered Fibers and Fabrics, 2012, 7 (4): 113-121. 